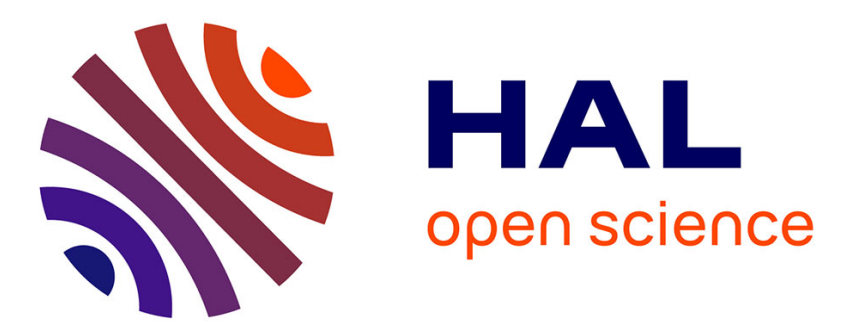

\title{
Active insulation technique applied to the experimental analysis of a thermodynamic control system for cryogenic propellant storage
}

\author{
Samuel Mer, Jean-Paul Thibault, Christophe Eric Corre
}

\section{To cite this version:}

Samuel Mer, Jean-Paul Thibault, Christophe Eric Corre. Active insulation technique applied to the experimental analysis of a thermodynamic control system for cryogenic propellant storage. Journal of Thermal Science and Engineering Applications, 2016, 8, 10.1115/1.4032761 . hal-01516090

\author{
HAL Id: hal-01516090 \\ https://hal.science/hal-01516090
}

Submitted on 19 Mar 2020

HAL is a multi-disciplinary open access archive for the deposit and dissemination of scientific research documents, whether they are published or not. The documents may come from teaching and research institutions in France or abroad, or from public or private research centers.
L'archive ouverte pluridisciplinaire HAL, est destinée au dépôt et à la diffusion de documents scientifiques de niveau recherche, publiés ou non, émanant des établissements d'enseignement et de recherche français ou étrangers, des laboratoires publics ou privés. 


\section{Active Insulation Technique Applied to the Experimental Analysis of a Thermodynamic Control System for Cryogenic Propellant Storage}

A technological barrier for long-duration space missions using cryogenic propulsion is the control of the propellant tank self-pressurization $(S P)$. Since the cryogenic propellant submitted to undesired heat load tends to vaporize, the resulting pressure rise must be controlled to prevent storage failure. The thermodynamic vent system (TVS) is one of the possible control strategies. A TVS system has been investigated using on-ground experiments with simulant fluid. Previous experiments performed in the literature have reported difficulties to manage the thermal boundary condition at the tank wall; spurious thermal effects induced by the tank environment spoiled the tank power balance accuracy. This paper proposes to improve the experimental tank power balance, thanks to the combined use of an active insulation technique, a double envelope thermalized by a water loop which yields a net zero heat flux boundary condition and an electrical heating coil delivering a thermal power $\mathcal{P}_{c} \in[0-360] W$, which accurately sets the tank thermal input. The simulant fluid is the NOVEC $C_{1230}$ fluoroketone, allowing experiments at room temperature $T \in[40-60]^{\circ} \mathrm{C}$. Various SP and TVS experiments are performed with this new and improved apparatus. The proposed active tank insulation technique yields quasiadiabatic wall condition for all experiments. For TVS control at a given injection temperature, the final equilibrium state depends on heat load and the injection mass flow rate. The cooling dynamics is determined by the tank filling and the injection mass flow rate but does not depend on the heat load $\mathcal{P}_{c}$.
Samuel Mer

LEGI,

University of Grenoble Alpes, Grenoble Cedex 9 38041, France samuel.mer@legi.grenoble-inp.fr

Jean-Paul Thibault LEGI,

University of Grenoble Alpes, Grenoble Cedex 9 38041, France jean-paul.thibault@legi.cnrs.fr

Christophe Corre

LMFA

Ecole Centrale de Lyon,

36 Avenue Guy de Collongue, Ecully Cedex 69134, France christophe.corre@ec-lyon.fr

\section{Introduction}

Future operations in space exploration will require the ability to store cryogenic liquids for long duration. Residual heat loads due to sun or heat conduction in the launcher structure induce cryogenic propellant vaporization and tank SP. Due to the extended duration of the mission, an uncontrolled tank SP may lead to storage failure.

A first control strategy, known as direct venting (DV), consists in a safety relief valve, venting the tank at a desired maximum pressure. The main shortcoming of this attractively simple technique is the fact that in space, due to microgravity effects, the phase (liquid or vapor) at which the propellant is vented remains undetermined while any liquid phase venting is strongly propellant consuming. Since no currently available technological device permits to create a DV system releasing only vapor from the tank ullage, this study focuses on another alternative control strategy, known as TVS. The first advantage of the system schematized in Fig. 1 is to ensure that the vented propellant phase is vapor. It relies on the following key ideas: thanks to a liquid-acquisition device (see Ref. [1] for more details), some liquid propellant is pumped from the tank to a heat exchanger in order to be subcooled. The subcooled liquid fraction is reinjected inside the tank as a jet or a spray in both vapor and liquid phase. In order to create the heat exchanger cold source (heat sink), another liquid fraction is withdrawn from the tank (vented branch), expanded through a Joule-Thomson valve and thus cooled down. Once used as the cold source, this liquid fraction is vented out of the tank as a vapor phase and lost for the mission (excepting the use of the venting thrust). The subcooled injection is followed by a vapor condensation and a liquid bath destratification which tends to depressurize the tank.

Since 1960s, NASA has developed a strong experience with cryogenic propellant management. Initial works combined

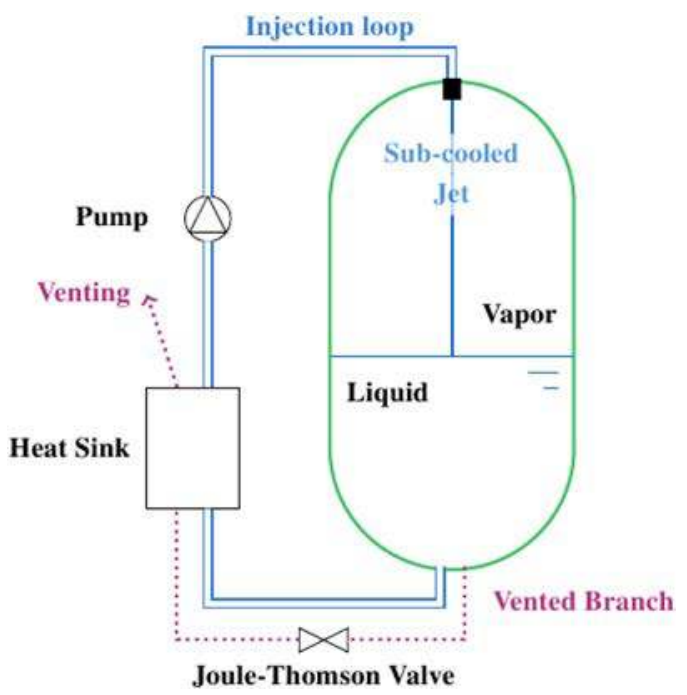

Fig. 1 Schematic view of a TVS controlled tank. The injection (loop) drives directly a subcooled jet inside the ullage. The vented branch creates the cold source heat sink. 
experiments in low gravity environment with the Aerobee sounding rocket program [2-5] and thermodynamic analysis of various control strategies [6,7]. As a consequence of the very difficult management of experiments conducted in an autonomous space mission, a limited amount of reliable data was produced by the Aerobee experimental program. To facilitate the management of experimental conditions, NASA turned to on-ground experimental facility using cryogens.

Hasan et al. [8] presented a series of SP experiment performed in a $4.95 \mathrm{~m}^{3}$ partially filled liquid hydrogen tank. The experiments were run around $30 \mathrm{~K}$. In those experiments, the driving potential for incident heat flux at the tank wall was consequent. The incident heat load was thus not an independent parameter (imposed by an electrical heating coil) but was instead computed from measured steady-state boil-off rates (see Ref. [9] for the complete calculation of the incident heat load). This computation gives access to the tank power balance and permits to confront experimental trends to the one predicted by a thermodynamic model. However, the measure has inherent and inevitable inaccuracy.

In order to relax constraints induced by the use of cryogens, and thus improve the accuracy of the tank power balance, Meserole et al. [10] performed thermal stratification, SP, and pressure control experiments using Freon as simulant fluid. The use of Freon, as a simulant fluid, allows experiment close to room temperature $\left(20^{\circ} \mathrm{C}\right)$ and thus lowers the driving potential for uncontrolled heat flux at the tank wall.

With the development of numerical fluid simulation, a substantial effort was dedicated to mass transfer modeling for these experimental configurations, first using global thermodynamic model [11-13] and more recently taking advantage of computational fluid dynamics solvers $[14,15]$. The agreement between experiments and numerical results remains, however, limited due to the difficulty of developing a predictive mass transfer model but also to the limited amount of reliable experimental data needed to calibrate and validate the numerical solvers.

Recent experimental works were devoted to on-ground TVS experiments using simulant fluid. The most relevant studies were performed by Barsi [16] in the U.S. and Demeure [17] in France. Both experimentally studied tank SP and TVS system with simulant fluids (respectively, $\mathrm{HFE}_{7000}$ and $\mathrm{NOVEC}_{1230}$ ). Their work confirmed the interest of TVS system to manage tank SP in the context of long-duration space mission. In particular, Barsi

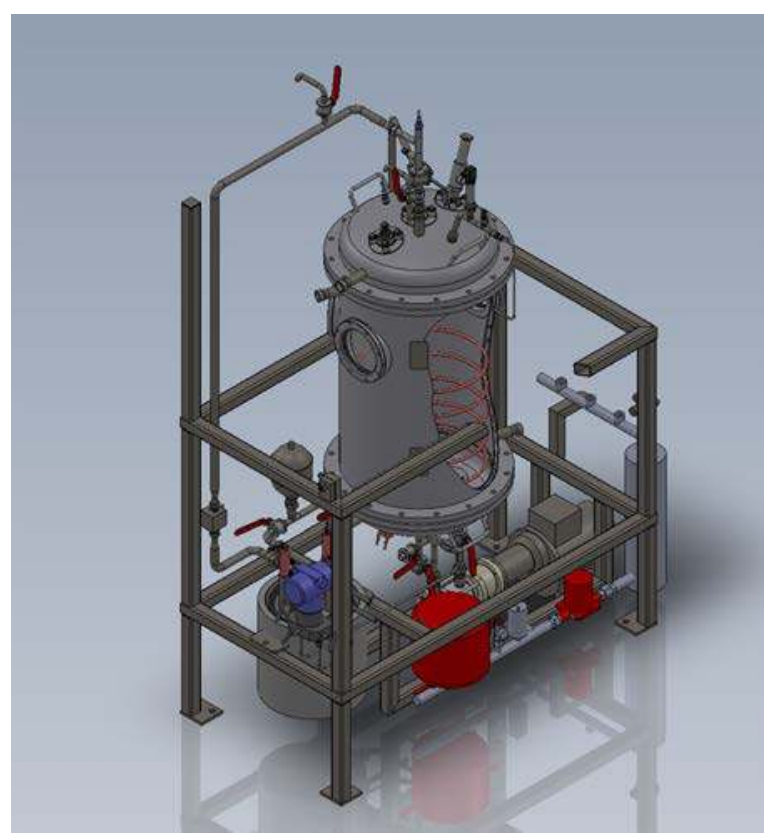

Fig. 2 Partially flayed CAD view of the experimental apparatus showed [18] that passive pressure control (i.e., without subcooling) can reduce pressure in the tank but only for a short period of time. To sustain the pressure reduction, energy needs to be continually withdrawn from the vapor-liquid system, for example, by subcooling the mixing jet. Moreover, Demeure demonstrated in Ref. [17], using a global thermodynamic model, that a properly designed TVS reduces cryogenic propellant consumption compared to an idealized DV system, i.e., where it is assumed only vapor is vented out of the tank in the DV configuration. However, both works $[16,17]$ evidenced the difficulty to manage tank wall boundary conditions so as to minimize the discrepancies between actually observed experimental trends and the ones theoretically expected. For instance, Barsi SP experiment tends to deviate from the expected linear pressure rise because of thermal leaks. The explanation provided in Ref. [19] is that as the applied heat load increased and the sensible energy of the system rises, the driving potential for heat loss between the test tank and the ambient surroundings increased as well. If the net heat flow leaking from the tank was constant, the pressurization rate would be expected to linearly increase with heat power. Similarly, the final plateautemperature of Demeure TVS experiment deviates from the one predicted by a thermodynamic analysis because the assumed adiabatic conditions were not properly ensured in practice. Both Refs. [16] and [17] concluded that temperature evolution measurements were spoiled by some undesired heat exchange with the tank environment. Besides, these experiments did not allow to assess the fluid thermal stratification as the tank instrumentation did not include vertically distributed temperature sensors.

The present work aims at providing a reliable database of SP and TVS control experiments in order to improve the understanding and modeling of heat and mass transfer phenomena occurring for these flow configurations and to validate numerical models. To fulfill this objective, our work experimentally investigates SP and TVS pressure control, thanks to an on-ground experimental facility using a simulant fluid. An active insulation technique, which yields a net zero heat flux boundary condition, is proposed. The performance of the technique is demonstrated for several SP and TVS experiments. A dedicated multisensor temperature probe is also designed to measure the vertical temperature distribution. A series of SP and TVS experiments are performed with this new and improved apparatus and are carefully analyzed.

\section{Experimental Apparatus}

The central component of the experiment is a $110 \mathrm{~L}$ tank displayed in Fig. 2. Following Ref. [17], a simulant fluid called

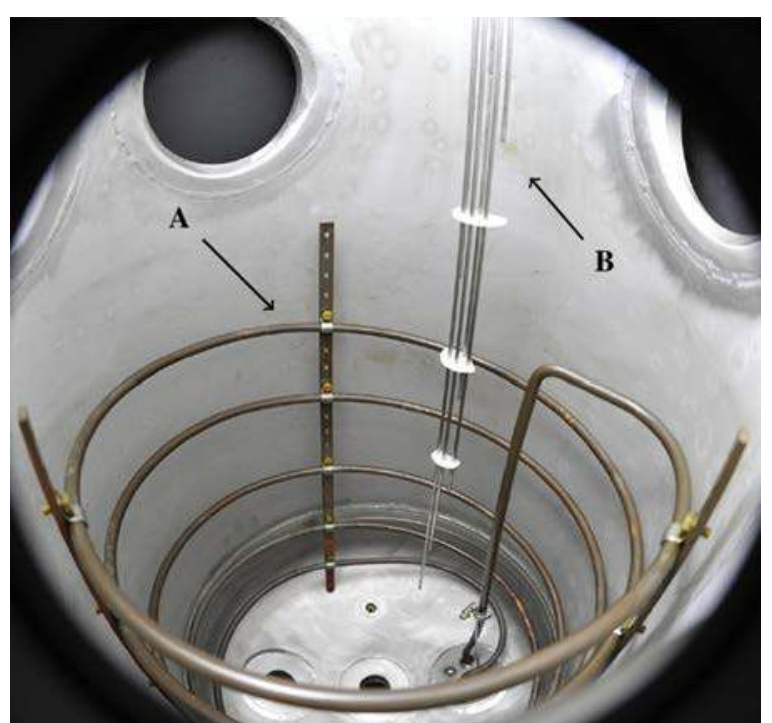

Fig. 3 Tank inside picture with the helicoidal heating coil $(A)$ and the multisensor temperature probe $(B)$ 


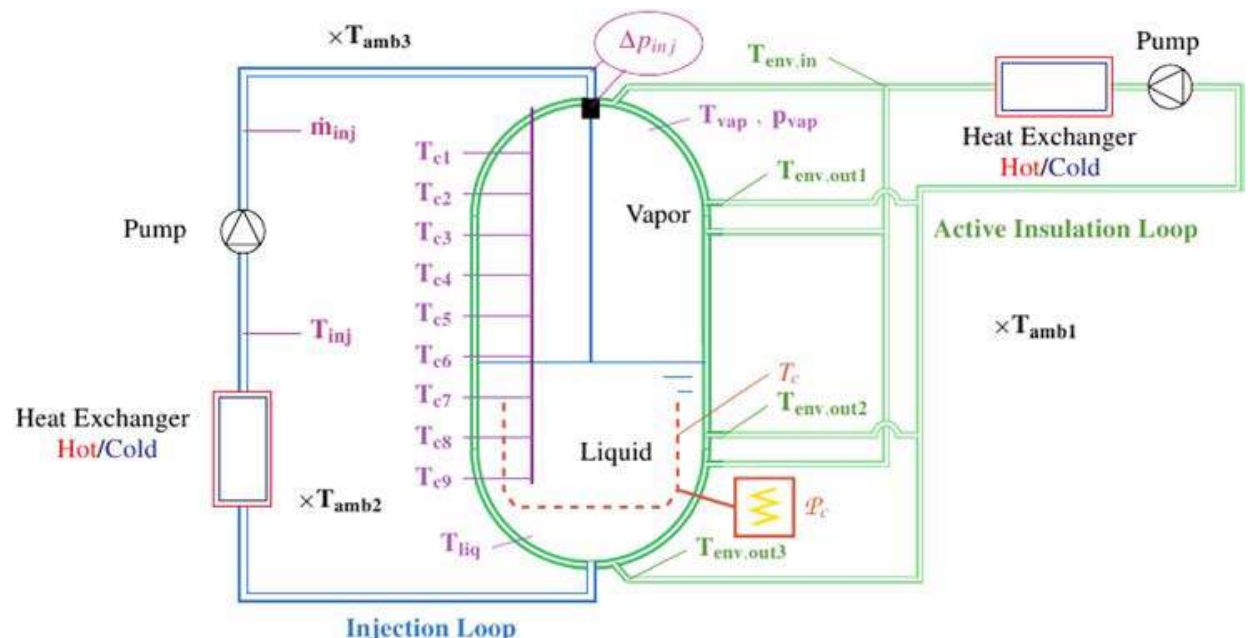

Fig. 4 Schematic view of the experimental facility with its instrumentation, injection loop, and double envelope temperature regulation

$3 \mathrm{M}^{\mathrm{TM}} \mathrm{NOVEC}_{1230}$, dodecafluoro-2-methylpentan-3-one of chemical formula $\mathrm{CF}_{3} \mathrm{CF}_{2} \mathrm{C}(\mathrm{O}) \mathrm{CF}\left(\mathrm{CF}_{3}\right)_{2}$, is used to enable experiment close to room temperature since the $\mathrm{NOVEC}_{1230}$ saturation temperature at atmospheric pressure is such that [20]

$$
T_{\text {sat } N_{120 V E C}}\left(P_{\text {atm }}\right)=50^{\circ} \mathrm{C}
$$

The tank heat load $\mathcal{P}_{c}$, representative of the heat load induced by insulation imperfections in a real space mission, is imposed by an electrical heating coil immersed in the liquid bath (see Fig. 3). The helicoidal heating coil has a heat exchange surface with the fluid equal to $0.208 \mathrm{~m}^{2}$. It delivers a heat power ranging between $0 \mathrm{~W}$ and $360 \mathrm{~W}$, which corresponds to a maximum heat flux of $0.2 \mathrm{~W} \mathrm{~cm}^{-2}$. The heating configuration is different from a real space mission configuration where the heat load is imposed at the tank wall. Any attempt to experimentally impose an adjustable heat flux at the wall of the apparatus proves rather unreliable. The present novel experimental choice is, to the best of our knowledge, the best way to control the net heating power. In fact, the heating power $\left(\mathcal{P}_{\mathrm{c}}\right)$ is imposed, thanks to the power supply to the heating coil, meanwhile the wall conditions verify a net zero heat flux. However, the heat load configuration difference might have some influence on thermal stratification. An active insulation technique is implemented in order to obtain a net zero heat flux as a wall boundary condition for the fluid. For this purpose, the tank walls are thermalized by a water loop circulating in a double envelope (see active insulation loop in Fig. 4). By equalizing the water temperature with the average temperature inside the tank $T_{\text {ave }}$ (see Sec. 2.2), one can cancel the net heat flux (through the tank wall) from the fluid to the tank wall. In other words, the water circulating in the envelop thermally separates the contained fluid from its environment. When the heat power supplied by the regulation to the water equals the ambient cooling power, no net heat flux does exist between the fluid in the tank and its environment. Consequently, the fluid in the tank is no longer affected by the natural convection in the room. The blue loop in Fig. 4 represents the injection loop, where a liquid fraction is pumped from the tank, subcooled in a heat exchanger, and reinjected as a jet inside the tank.

2.1 Instrumentation. A multisensor temperature probe has been specially developed to measure the vertical temperature distribution in the tank (see Fig. 3). It is made of nine PT100 sensors regularly spaced along the vertical. Other control sensors (see Fig. 4) give, respectively, access to the tank filling, the injection mass flow rate $\dot{m}_{\text {inj }}$; the injection temperature $T_{\mathrm{inj}}$; the pressure drop through the injector $\Delta P_{\text {inj; }}$; the vapor pressure $P_{\text {vap }}$; the vapor temperature $T_{\text {vap }}$ at the top of the tank and the liquid temperature $T_{\text {liq }}$ at the bottom of the tank; the double envelop water circuit temperatures $T_{\text {env,in }}, T_{\text {env,out } 1}, T_{\text {env,out } 2}$ and $T_{\text {env,out } 3}$; and the ambient temperatures $T_{\mathrm{amb} 1}, T_{\mathrm{amb} 2}$, and $T_{\mathrm{amb} 3}$. A temperature sensor is fastened to the heating coil $T_{\text {coil }}$ (see Figs. 3 and 4 ) to measure the temperature imbalance induced by the heat power supply. The acquisition chain is identical for all the temperature sensors. The PT100 sensors are connected to a data recorder of Versadac ${ }^{\mathrm{TM}}$ Eurotherm type. This data recorder converts the sensors analogical signal into a numerical one and communicates by Ethernet with two controllers (Nanodac Eurotherm). Each controller manages a proportional-integral-derivative (PID) control loop (see injection loop and active insulation loop in Fig. 4). The controllers are connected to a computer where the control loops are set up and the PID parameters are tuned. The computer stores and analyzes the experimental data. The whole temperature-acquisition chain has been calibrated to minimize the measurement error $\left(\Delta T \approx \pm 0.05^{\circ} \mathrm{C}\right)$.

2.2 Active Insulation Technique. The average temperature inside the tank $T_{\text {ave }}$ is computed as the arithmetic average of all the sensors inside the tank weighted by their respective heat capacity (either liquid or vapor). The heat-capacity based weight allows to take into account the thermal inertia of each phase in the average calculation

$$
T_{\text {ave }}=\frac{\sum_{\text {sens. }} \rho_{i}\left(T_{\text {sensor }}\right) \cdot c_{\mathrm{p}, i}\left(T_{\text {sensor }}\right) \cdot T_{\text {sensor }}}{\sum_{\text {sens. }} \rho_{i}\left(T_{\text {sensor }}\right) \cdot c_{\mathrm{p}, i}\left(T_{\text {sensor }}\right)}, i \in[\mathrm{vap}, \text { liq }]
$$

The temperature of the water circulating in the double envelope is PID controlled to follow $T_{\text {ave }}$ plus a compensation factor $\beta$ $\left(T_{\text {env }}-T_{\text {amb }}\right)$, which has been experimentally determined through the following procedure. The envelope temperature is forced to a typical value (for instance, $T_{\mathrm{env}}=40^{\circ} \mathrm{C}$ ). Once the thermal equilibrium is reached in the tank (typically after $6 \mathrm{hrs}$ ), the temperature difference $\left(T_{\text {env }}-T_{\text {ave }}\right)$ is recorded along with the temperature difference $\left(T_{\mathrm{env}}-T_{\mathrm{amb}}\right)$. By iterating this procedure for different envelop temperatures, the compensation factor function can be derived from plotting $\left(T_{\text {env }}-T_{\text {ave }}\right)$ versus $\left(T_{\text {env }}-T_{\text {amb }}\right.$ ) (see Fig. 5). The trend line obtained is an affine function $(y=a \cdot x+b)$. However, coefficient $b$ is within our temperature measurement error $\left(b=-0.028<0.05^{\circ} \mathrm{C}\right)$ and does not carry a physical significance anyway; therefore, the compensation 


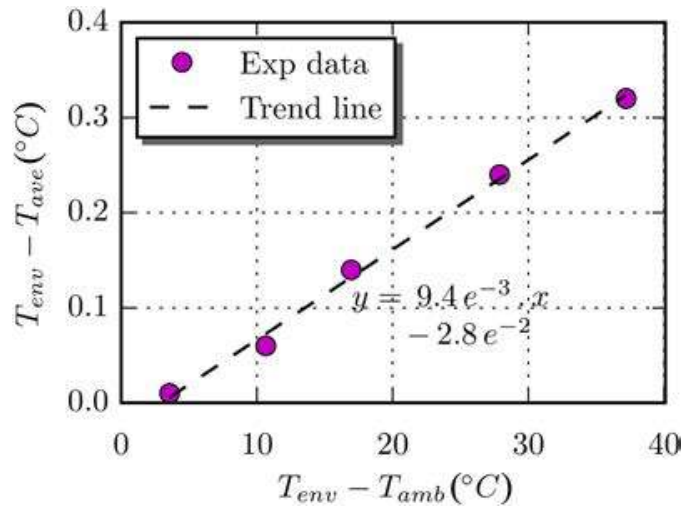

Fig. 5 Experimental determination of the compensation factor $\beta\left(T_{\text {env }}-T_{\mathrm{amb}}\right)$ applied to the PID regulation set-point

factor selected for the PID regulation is a linear function of the temperature imbalance between $T_{\text {env }}$ and $T_{\text {amb }}$

$$
\beta \cdot\left(T_{\mathrm{env}}-T_{\mathrm{amb}}\right)=9.4 \times 10^{-3} \times\left(T_{\mathrm{env}}-T_{\mathrm{amb}}\right)
$$

In the following paragraph, the prescribed envelope temperature regulation set-point is denoted $T_{\text {env,SP }}$ while the current envelope temperature working-point is denoted $T_{\text {env,wP. Figures } 6 \text { and } 7}$ illustrate the benefit of the active insulation for a typical plateautemperature at $40{ }^{\circ} \mathrm{C}$ and demonstrate the importance of the compensation factor $\left(\beta\left(T_{\mathrm{env}, \mathrm{WP}}-T_{\mathrm{amb}}\right)\right)$ to achieve the targeted regulation performance. When the compensation factor is taken into account $T_{\mathrm{env}, \mathrm{SP}}=T_{\mathrm{ave}}+\beta\left(T_{\mathrm{env}, \mathrm{WP}}-T_{\mathrm{amb}}\right)$, the plateautemperature is precisely maintained during $6 \mathrm{hrs}$ without any drift (see Fig. 6). On the other hand, if the compensation factor is set to zero $T_{\text {env,SP }}=T_{\text {ave }}$, one can observe in Fig. 7 that even when $T_{\text {env,SP }}=40^{\circ} \mathrm{C}$ is forced during the first $30 \mathrm{~min}$ of the test, $T_{\text {ave }}$ never reaches this value. Once the active insulation technique is turned-on (after $30 \mathrm{~min}$ and without compensation factor), a linear temperature drift is observed, which is due to the envelop convective heat exchange with the ambient room. This comparison between an experiment with and without compensation factor clearly demonstrates that the compensation factor accurately counterbalances the convective heat loss (experiment/room). The wall condition is not strictly adiabatic because ullage and liquid temperatures are not locally equal to $T_{\text {env }}$. The effective thermal boundary condition at the tank wall is a uniform wall temperature (double envelop) which satisfies a net zero heat flux.

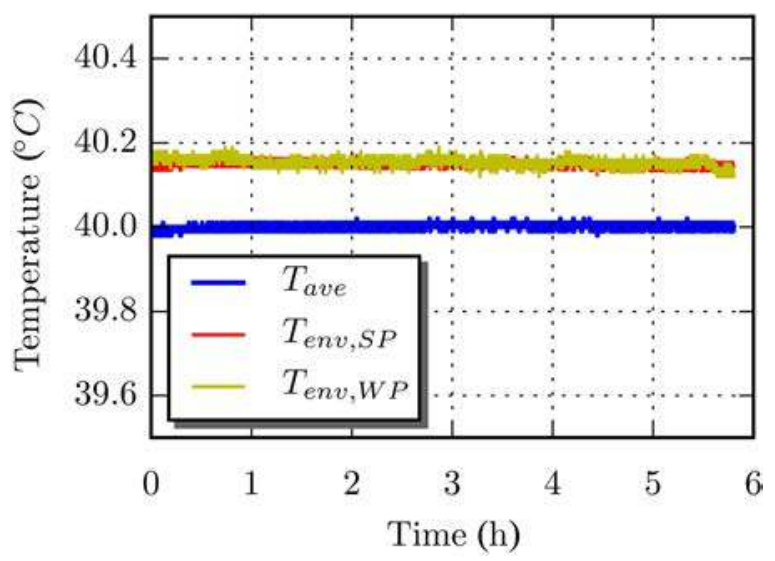

Fig. 6 Typical temperature plateau performance of the active insulation technique with compensation factor - $\left(T_{\text {env,Sp: regu- }}\right.$ lation set-point $-T_{\text {env,wp: regulation working-point) }}$

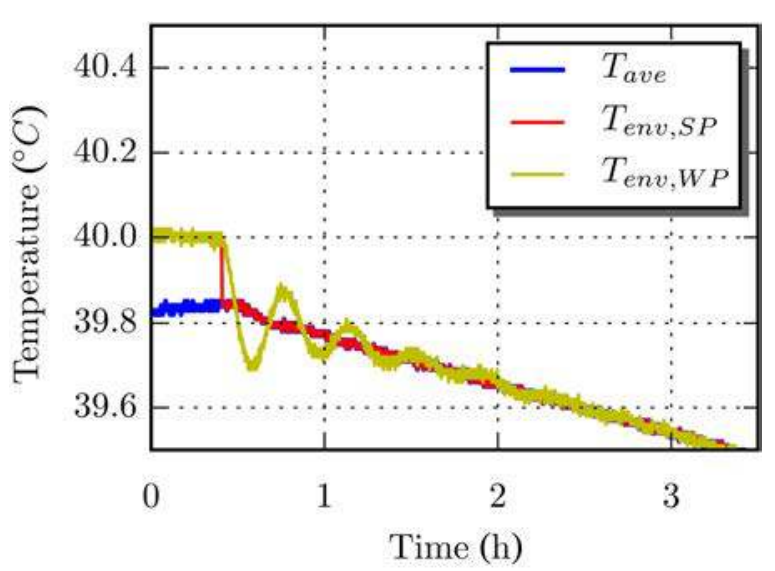

Fig. 7 Typical temperature plateau performance of the active insulation technique without compensation factor $-\left(T_{\text {env,SP: }}\right.$ regulation set-point $-T_{\text {env,wp: regulation working-point) }}$

2.3 Fluid Purity Assessment. Since the physical phenomenon under study is a single species problem, involving a liquid and its vapor, it is essential to assess flow purity in the experimental tank in order to remain representative of the real system. For example, Bullard [21] showed that the presence of noncondensable gases significantly increases the characteristic cooling time (see Sec. 3.2) of a TVS control phase.

A purification procedure has been developed to purify the fluid by venting out the noncondensable gases. To do so, the tank is filled until overflowing by a top drain. Thanks to the envelope temperature regulation, the temperature inside the tank can be prescribed (for example, $T_{\mathrm{ave}}=50^{\circ} \mathrm{C}$ ). A drain located at the top of the tank allows to impose the atmospheric pressure in the tank. The fluid can thus be brought to saturation $T_{\text {sat }}(1$ bar $)=50^{\circ} \mathrm{C}$. Since the solubility of noncondensable gases tends to zero when the fluid is close to saturation, noncondensable gases can be vented out by the top drain. Flow purity is assessed by comparing the measured $P_{\text {vap }}$ with the saturation pressure extrapolated from the interface temperature $P_{\text {sat }}\left(T_{\text {inter }}\right)$. This extrapolation is based on the physical properties of NOVEC ${ }_{1230}$ (Clausius Clapeyron saturation equation [20]). Due to the residual content of noncondensable gases and fluid impurities (the fluid has an industrial grade corresponding to a $99 \%$ purity), a perfect agreement between the measured $P_{\text {vap }}$ and $P_{\text {sat }}\left(T_{\text {inter }}\right)$ was never reached in the experiments. The observed pressure offset corresponds to the partial pressure of noncondensable gases $P_{\text {noncond }}=P_{\text {vap }}-P_{\text {sat }}\left(T_{\text {inter }}\right)$. For all the results presented in this work, the partial pressure of noncondensable gases in the tank was always below $71 \times 10^{-3}$ bar which corresponds to a molar fraction of noncondensable

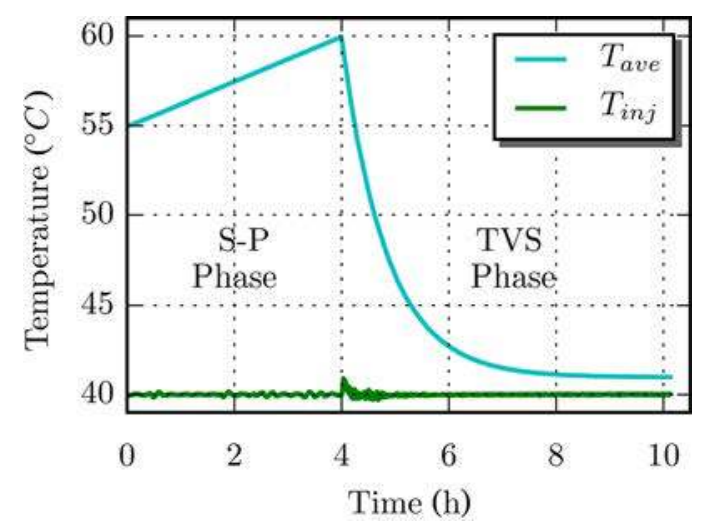

Fig. 8 Typical results of an experiment: SP experiment followed by a TVS control phase 
gases below 6\%. Similar residual pressure level has already been noticed in the literature whatever the purification method is. For instance, Barsi [16] used an iterative procedure using a vacuum pump to degas its simulant fluid. A $4 \%$ residual noncondensable molar fraction was observed in his apparatus after iterating its vacuum purification procedure several times. This level is slightly better than the one provided by the present purification technique but considering implementation complexity and time process duration arguments, it was decided that the $2 \%$ gain was not worth the investment.

\section{Analysis of Experimental Results}

A typical experiment can be decomposed into two phases (see Fig. 8). The first phase is the SP phase, where temperature and pressure linearly increase in the tank due to the heat power supply. A perfect linear rise is obtained only if the wall boundary condition is adiabatic (the experimental boundary condition is a net zero heat flux). The pressure rise slope depends on the tank heat load imposed by the heating coil and the initial tank filling. Once a maximum pressure is reached in the tank, the TVS control is activated and a subcooled jet is injected inside the tank at a fixed mass flow rate $\dot{m}_{\text {inj }}$ and temperature $T_{\text {inj. }}$.

In this section, the experimental results of both SP and TVS control phases are compared to the results of the thermodynamic model developed by Demeure. This model, OD but timedependent, uses an adiabatic wall boundary condition and solves thermodynamic balance equations to predict the tank pressure and temperature evolutions. For more details on the modeling technique and the model assumptions, refer to Refs. [17] and [22]. As described by the model, the TVS subcooled injection leads to an exponential temperature decay characterized by two parameters $\tau_{\mathrm{ES}}$ and $T_{\mathrm{ES}}$ (see Fig. 9). The characteristic cooling time $\tau_{\mathrm{ES}}$ assesses the cooling rate, while the final plateau-temperature $T_{\mathrm{ES}}$ characterizes the equilibrium state reached at the end of the permanent injection.

3.1 SP. In the experiments presently discussed, the initial condition for a SP phase is a plateau-temperature at $T_{\text {ave }}=55^{\circ} \mathrm{C}$ in the tank. Due to coil heating, the pressure rises linearly in the tank as illustrated in Figs. 10 and 11. The SP ends when the tank average temperature reaches $T_{\text {ave }}=60^{\circ} \mathrm{C}$. The experimental results are compared with the prediction of a thermodynamic model taking into account an adiabatic wall boundary condition (see Table 1). A very good agreement observed, for an 8-hr experiment, with the linear pressure rise predicted by an adiabatic thermodynamic model demonstrates that the net zero heat flux wall boundary condition effectively tends toward an adiabatic wall boundary condition.

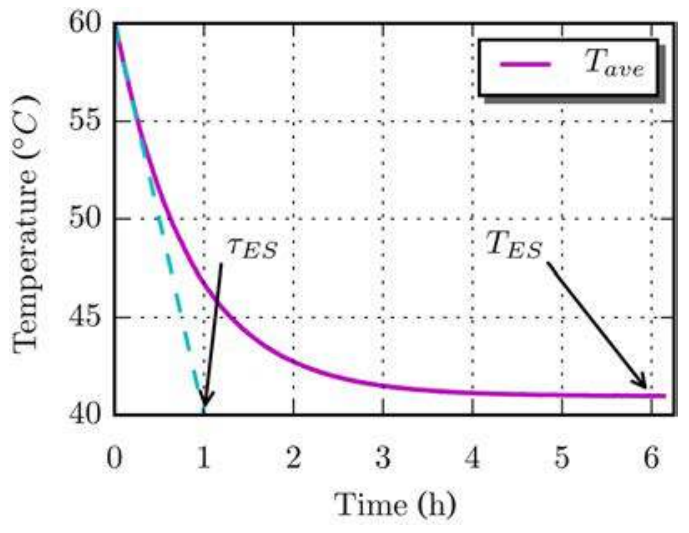

Fig. 9 The temperature exponential decay observed during TVS control is characterized by a characteristic cooling time $\tau_{\text {ES }}$ and a final temperature-plateau $T_{E S}$

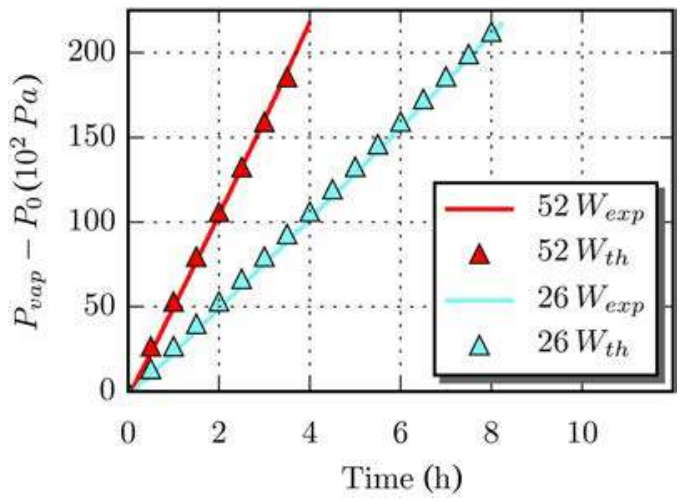

Fig. 10 SP experimental results (solid lines) compared to an adiabatic thermodynamic model (symbols) for various values of the coil heating power $\mathcal{P}_{c}$. Liquid tank filling set equal to $66 \%$.

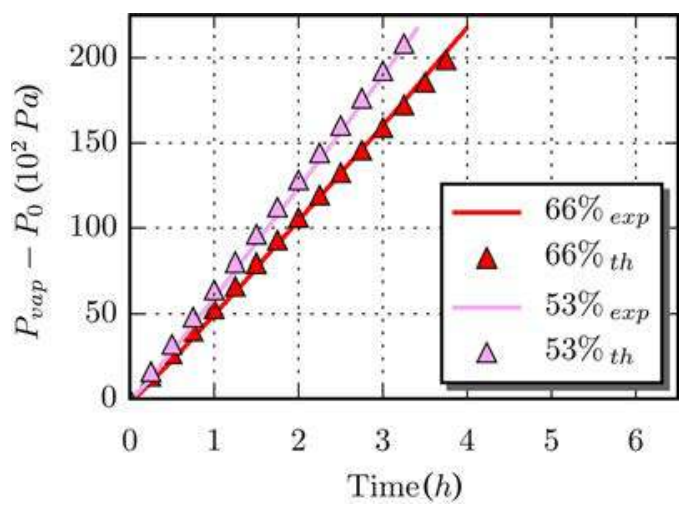

Fig. 11 SP experimental results (solid lines) compared to an adiabatic thermodynamic model (symbols) for various values of the initial tank filling. Coil heating power set equal to $52 \mathrm{~W}$.

As shown by the calculation of the SP time in Table 1, the higher the coil power, the faster the SP and similarly the lower the tank filling, the steeper the pressurization rate due to a smaller sensible heat capacity of the fluid inside the tank. These straightforward experimental trends are in agreement with the ones predicted by an adiabatic thermodynamic model and with the previous works available in the literature $[8,19]$. The linear pressure rise achieved in the present study demonstrates the efficiency of the proposed active insulation technique and also the fact it does not affect the pressurization dynamics, even when the thermal imbalance increases between the experimental fluid and the ambient room.

3.2 TVS Injection. As explained in Sec. 1, the TVS injection is activated once the pressure has reached a maximum value in the tank, which leads to an exponential temperature decay (see Fig. 9) characterized by a cooling time $\tau_{\mathrm{ES}}$ and a final equilibrium temperature $T_{\text {ES }}$. Following Ref. [17], both parameters can be expressed, using an ideal adiabatic thermodynamic model, as

Table 1 Comparison of the experimental SP time with an adiabatic thermodynamic model

\begin{tabular}{lcccc}
\hline \hline Tank filling $(\%)$ & $\mathcal{P}_{\mathrm{c}}(\mathrm{W})$ & $t_{\text {SPexp }}(\mathrm{hr})$ & $t_{\text {SPadiab }}(\mathrm{hr})$ & $\Delta(\%)$ \\
\hline 66 & 26 & 8.17 & 8.23 & 0.7 \\
66 & 52 & 3.99 & 4.09 & 2.4 \\
53 & 52 & 3.40 & 3.39 & 0.3 \\
\hline \hline
\end{tabular}




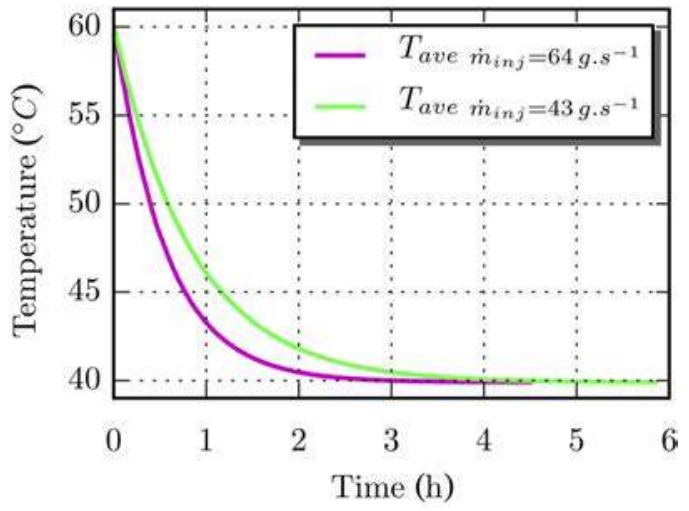

Fig. 12 Comparison of various TVS experiments for different $\dot{m}_{\text {inj }}$ and fixed tank filling: $66 \%-\mathcal{P}_{\mathrm{c}}=0 \mathrm{~W}-T_{\text {inj }}=40^{\circ} \mathrm{C}$

$$
\begin{gathered}
T_{\text {ES adiab }}=T_{\text {inj }}+\frac{\mathcal{P}_{\mathrm{c}}}{\dot{m}_{\text {inj }} \cdot c_{\mathrm{p}, \text { liq }}\left(T_{\text {inj }}\right)} \\
\tau_{\text {ES adiab }}=\frac{m_{\text {liq }}^{\text {init }} \cdot c_{\mathrm{p}, \text { liq }}\left(T_{\text {init }}\right)}{\dot{m}_{\text {inj }} \cdot c_{\mathrm{p}, \text { liq }}\left(T_{\text {inj }}\right)}
\end{gathered}
$$

Barsi [16,19] realized similar TVS experiments in a smaller tank $(\approx 15 \mathrm{~L})$ equipped with a bottom injection. The subcooled jet was indeed injected at the bottom of the tank in the liquid bath. To prevent geyser mode, the injection mass flow rate was limited to low values. A time delay between the injection start and the initiation of the pressure decrease was observed in the experiments reported in Refs. [16] and [19]. This delay was explained by the authors as due to a competition between natural convective recirculation in the tank liquid bath and the impinging forced subcooled jet. Furthermore, a dimensionless pressure reduction time was derived, based on Richardson and Reynolds numbers, to assess the depressurization dynamics (similar to the characteristic cooling time $\left.\tau_{\mathrm{ES}}\right)$. In our experimental apparatus, the injector is placed at the top of the tank, directly in the ullage. With such an injection configuration, the injection start and the initiation of the pressure decrease are perfectly synchronized. Indeed, due to the direct contact between the subcooled jet and the saturated ullage, the condensation effect induced by the jet starts immediately at the jet ignition and so the pressure decreases. Furthermore, as the injection location is different, the flow inside the tank is different and the pressure reduction time used by Barsi is not relevant for our configuration.

A series of TVS experiments have been performed for various values of tank heat load $\mathcal{P}_{\mathrm{c}}$, injection mass flow rate $\dot{m}_{\text {inj }}$, and initial tank filling. The measured temperature evolutions have been systematically compared with the adiabatic model prediction, in

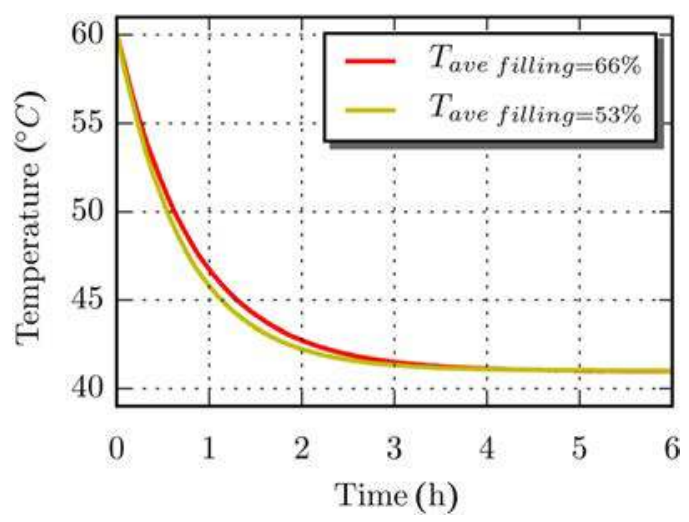

Fig. 14 Comparison of various TVS experiments for different tank filling and fixed $\mathcal{P}_{\mathrm{c}}=52 \mathrm{~W}-\dot{m}_{\mathrm{inj}}=43 \mathrm{~g} \mathrm{~s}^{-1}-T_{\mathrm{inj}}=40^{\circ} \mathrm{C}$
Table 2 Comparison of various experimental TVS final plateau-temperature $T_{\mathrm{ES}}$ with an adiabatic thermodynamic model

\begin{tabular}{lccccc}
\hline \hline$\dot{m}_{\text {inj }}\left(\mathrm{g} \mathrm{s}^{-1}\right)$ & Tank filling $(\%)$ & $\mathcal{P}_{\mathrm{c}}(\mathrm{W})$ & $T_{\text {ESexp }}\left({ }^{\circ} \mathrm{C}\right)$ & $T_{\text {ESadiab }}\left({ }^{\circ} \mathrm{C}\right)$ & $\Delta_{\mathrm{T}}(\%)$ \\
\hline 43 & 66 & 0 & 39.91 & 40.00 & 0.2 \\
64 & 66 & 0 & 39.90 & 40.00 & 0.2 \\
43 & 66 & 26 & 40.44 & 40.54 & 0.2 \\
43 & 66 & 52 & 40.97 & 41.09 & 0.3 \\
43 & 53 & 52 & 41.02 & 41.09 & 0.2 \\
\hline \hline
\end{tabular}

Table 3 Comparison of various experimental TVS characteristic cooling time $\tau_{E S}$ with an adiabatic thermodynamic model

\begin{tabular}{lccccc}
\hline \hline$\dot{\dot{m}_{\text {inj }}\left(\mathrm{g} \mathrm{s}^{-1}\right)}$ & Tank filling $(\%)$ & $\mathcal{P}_{\mathrm{c}}(W)$ & $\tau_{\text {ESexp }}(\mathrm{s})$ & $\tau_{\text {ESadiab }}(\mathrm{s})$ & $\Delta_{\tau}(\%)$ \\
\hline 43 & 66 & 0 & 3025 & 2591 & 14 \\
64 & 66 & 0 & 2008 & 1727 & 14 \\
43 & 66 & 26 & 3025 & 2591 & 14 \\
43 & 66 & 52 & 3003 & 2591 & 14 \\
43 & 53 & 52 & 2598 & 2123 & 18 \\
\hline \hline
\end{tabular}

terms of characteristic cooling time and final plateau-temperature. Figures 12-14 display the respective effect of $\dot{m}_{\text {inj }}, \mathcal{P}_{\mathrm{c}}$, and initial tank filling on the measured temperature decrease. Table 2 summarizes the measured plateau-temperature $T_{\mathrm{ES} \text {,exp }}$, its expected value $T_{\mathrm{ES} \text { adiab }}$ provided by the adiabatic thermodynamic model, and the difference between the two values for the various combinations of injection mass flow rate, heat load, and initial tank filling investigated. Table 3 provides similar information for the characteristic cooling time $\tau_{\mathrm{ES}}$.

3.2.1 Sensitivity Analysis. It can be observed, in Fig. 12 and in Table 3, that an increase of $\dot{m}_{\text {inj }}$ results in a faster cooling rate, as predicted by the thermodynamic model. Furthermore, at a given injection temperature, the coil power only affects the final plateau-temperature and not the cooling rate (see Fig. 13 and Table 2). Reasoning on heat capacity, one can straightforwardly expect tank filling to have an effect on the cooling rate but not on the final equilibrium state. This expected trend can indeed be observed in Fig. 14 and in Tables 2 and 3. This is in accordance with the previous results published by Thibault et al. [22].

A very good agreement between the experiments and the adiabatic model prediction is systematically obtained in Table 2 for the plateau-temperature. This demonstrates again the good performance of the active insulation technique which yields quasiadiabatic wall boundary condition. However, a constant discrepancy is observed for the characteristic cooling time $\tau_{\mathrm{ES}}$ reported in Table 3. The next paragraph attempts to explain this observed discrepancy.

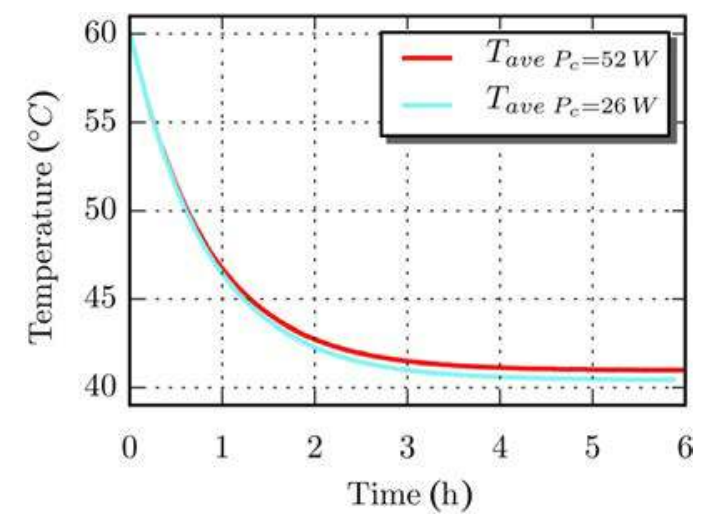

Fig. 13 Comparison of various TVS experiments for different $\mathcal{P}_{\mathrm{c}}$ and fixed tank filling: $66 \%-\dot{m}_{\mathrm{inj}}=43 \mathrm{~g} \mathrm{~s}^{-1}-T_{\mathrm{inj}}=40^{\circ} \mathrm{C}$ 
3.2.2 Tradeoff Choice for the PID Regulation. The 14-18\% discrepancy observed between the experiment and the adiabatic model for the dynamics of the TVS phase, namely, the prediction of the characteristic cooling time $\tau_{\mathrm{ES}}$, can be explained by the tradeoff to be necessarily made when setting the PID regulation parameters. Indeed, the SP and TVS dynamics are significantly different. The SP is characterized by a slow and linear temperature rise. Therefore, it is quite easy to set up PID regulation parameters such that the envelope temperature follows the average fluid temperature inside the tank. Reversely, TVS control is characterized by an exponential cooling rate with an unsteady cooling dynamics. The cooling power of the jet can be expressed as $P_{\text {coldjet }}=h \cdot S \cdot \Delta T_{\text {jet/fluid. }}$. As the injection goes on, the temperature difference between the subcooled jet (injection temperature $T_{\mathrm{inj}}$ ) and the average temperature of the fluid inside the tank $\left(T_{\text {ave }}\right)$ decreases. Thus, the cooling power decreases during the TVS phase until the temperature reaches its final equilibrium value $T_{\mathrm{ES}}$.

To ensure the envelope temperature correctly follows the unsteady dynamics, a multi-PID regulation has been set up. The multi-PID regulation technique is based on two sets of predefined PID parameters (one for each dynamics, see Fig. 15). A characteristic physical quantity representative of the temperature dynamics inside the tank allows, if compared to a predefined threshold, to select the appropriate set of PID parameters. In the case under study, the physical quantity characterizing the fluid temperature dynamics is the time variation of the average temperature inside the tank: $\left(\partial T_{\text {ave }} / \partial t\right)$. A first set, PID $_{1}$, is calibrated to fit the slow dynamics occurring during the SP and the end of the TVS phase. A second set, $\mathrm{PID}_{2}$, is calibrated to follow the fast temperature changes occurring during the early stages of the TVS phase. A sensitivity study has been performed to determine an appropriate threshold value $\left(\partial T_{\text {ave }} / \partial t\right)_{\text {tr }}$ to select the switch from one PID set to the other in such a way that this switch remains relevant for all the experimental dynamics encountered. In addition, this adjustment phase permitted the identification of the two parameter sets $\mathrm{PID}_{1}$ and $\mathrm{PID}_{2}$ that are able to manage envelope regulation for all the experiments realized. The selected tradeoff provides a satisfactory regulation performance, as observed from the previously analyzed results, but one can observe in Fig. 15 that in the early stage of the TVS injection the cooling dynamics is too fast inside the tank for the $\mathrm{PID}_{2}$ regulation to smoothly follow its set-point temperature $T_{\text {env,SP. The working-point }} T_{\text {env,WP }}$ oscillates before stabilizing at the set-point value when the cooling rate lowers. These oscillations impact the cooling dynamics inside the tank and thus explain the observed discrepancies between measurement and the thermodynamic model for the characteristic cooling time.

3.3 Thermal Stratification. The implemented instrumentation gives access to the vertical fluid temperature distribution in the

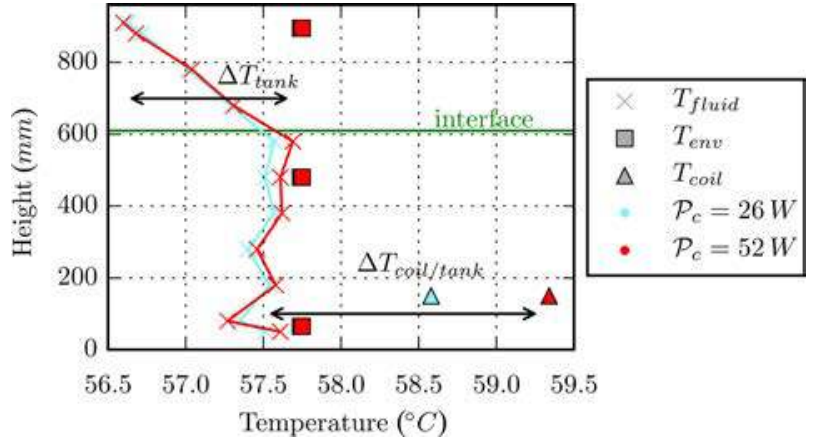

Fig. 16 Vertical temperature distribution in the fluid, heating coil temperature, and wall temperature (double envelope) during an SP phase and for two different heat loads: $\mathcal{P}_{c}=52 \mathrm{~W}$ and $\mathcal{P}_{c}=26 \mathrm{~W}$, both for $T_{\text {ave }}=57.5^{\circ} \mathrm{C}$

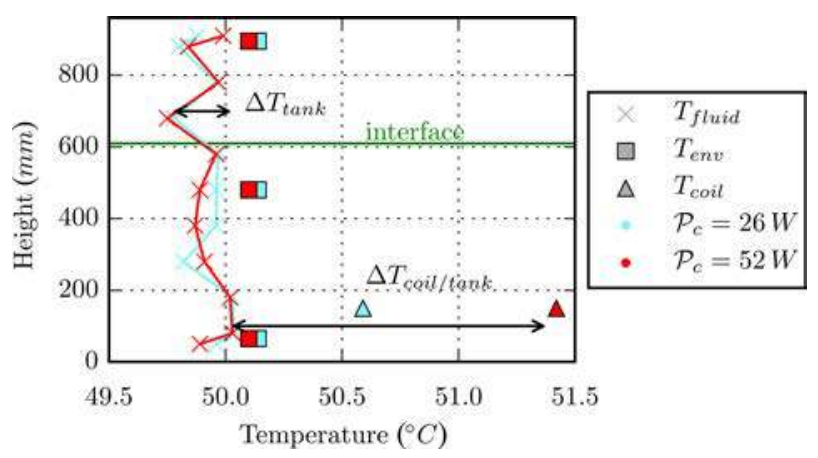

Fig. 17 Vertical temperature distribution in the fluid, heating coil temperature, and wall temperature (double envelope) during a TVS phase and for two different heat loads: $\mathcal{P}_{c}=52 \mathrm{~W}$ and $\mathcal{P}_{c}=26 \mathrm{~W}$, both for $T_{\text {ave }}=57.5^{\circ} \mathrm{C}$

tank (see Figs. 16 and 17). Thanks to the active insulation technique, which provides a quasi-adiabatic wall boundary condition, the temperature stratification inside the tank can be decoupled from the tank environment. The vertical temperature distribution is thus only affected by the tank internal thermal effects.

One can observe that the temperature distribution in the liquid phase is quite uniform during both the SP and TVS phases, because of the high thermal diffusivity of the liquid phase. During the SP phase (see Fig. 16), a conductive heat transfer mode induces a linear thermal stratification in the ullage from the hot interface to the top of the tank. During SP, the thermal stratification in the tank

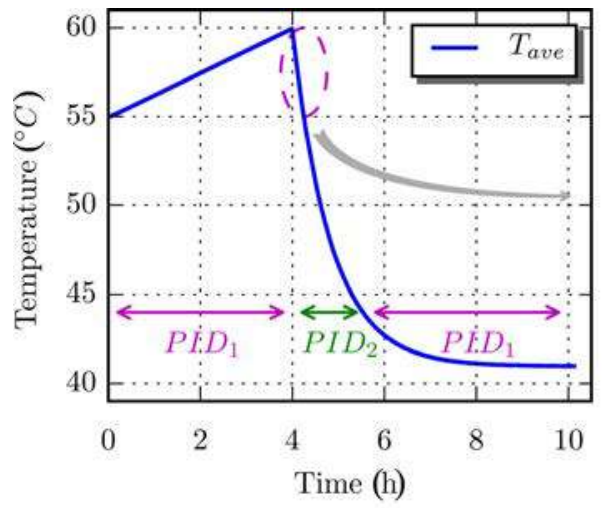

(a)

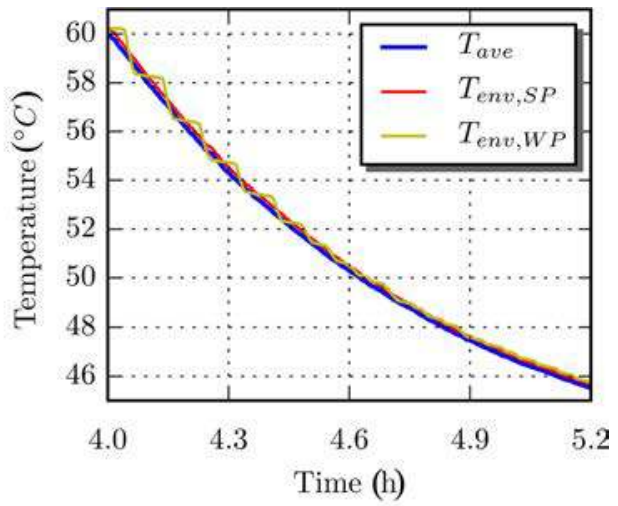

(b)

Fig. 15 Left: typical time evolution of the average temperature of the fluid inside the tank $T_{\text {ave }}$ along with a diagram of the multi-PID regulation principle. Right: focus on the early stage of the TVS injection with the envelope temperature regulation set-point $T_{\mathrm{env}, \mathrm{SP}}$ and the envelope temperature regulation working-point $T_{\text {env,wP. }}$ 
$\Delta T_{\text {tank }}$ is not affected by the heating coil power. The local temperature difference between the liquid and the coil is around $1{ }^{\circ} \mathrm{C}$.

During TVS injection (see Fig. 17), the subcooled jet induces a destratification effect in the ullage; the global stratification in the tank thus decreases to $\Delta T_{\text {tank }} \approx 0.3^{\circ} \mathrm{C}$. The temperature imbalance observed between the coil and the fluid $\Delta T_{\text {coil/tank }}$ (for both experimental phases) is a function of the coil heating power. The coil temperature depends on the convective heat exchange with the liquid bath $\mathcal{P}_{\mathrm{c}}=h \cdot S \cdot \Delta T_{\text {coil/tank }}$. For a given heat load, the coil convective heat transfer coefficient $h$ is affected by the subcooled jet. The jet improves mixing and, as a result, increases the convective heat exchange coefficient in the liquid bath. This effect is attested by the experimental value of the temperature imbalance induced by the coil. For instance, for a given tank heat load $\mathcal{P}_{\mathrm{c}}=26 \mathrm{~W}, \Delta T_{\text {coil } / \text { tank SP }}=1.1^{\circ} \mathrm{C}$ during SP (no jet) while $\Delta T_{\text {coil/tankTVS }}=0.6^{\circ} \mathrm{C}$ during TVS (with subcooled jet).

\section{Conclusion}

An active insulation technique has been proposed to thermally decouple a test tank from its environment in the context of SP and TVS control experiments of a heated tank initially filled with a liquid and its vapor at saturation conditions. The technique yields a net zero heat flux wall boundary condition which tends to a quasi-adiabatic wall boundary condition for all the experiments (SP and TVS with or without heat load $\mathcal{P}_{\mathrm{c}}$ ). With the tank thermally decoupled from its environment, the temperature stratification inside the tank and the temperature dynamics during SP and TVS injection are thus free from spurious effects induced by the tank environment, which were observed in previous experiments.

A small-scale experiment using a simulant fluid called NOVEC $_{1230}$ was performed in a normal gravity environment. During TVS control with the heating coil activated and for a fixed temperature injection $T_{\mathrm{inj}}$, the final plateau-temperature $T_{\mathrm{ES}}$ depends on the coil heating power $\mathcal{P}_{\mathrm{c}}$ and on the injection mass flow rate $\dot{m}_{\text {inj }}$. On the other hand, the characteristic cooling time $\tau_{\mathrm{ES}}$ depends on the initial tank filling and on the injection mass flow rate $\dot{m}_{\text {inj. }}$. The implemented instrumentation gives access to an accurate temperature distribution and to the pressure dynamics within the tank.

Future experimental work will focus on the analysis of other injection strategies such as injection at a fixed $\Delta T_{\mathrm{inj}}=T_{\text {liq }}-T_{\mathrm{inj}}$ instead of a fixed injection temperature $T_{\text {inj. }}$. Such a strategy will be more representative of the cooling effect of the Joule-Thomson valve used in the real space system. An injection nozzle will also be used to assess the impact of subcooled jet atomization on TVS performance. A wall-heating configuration might also be explored to assess the influence of heat load configuration on tank thermal stratification, namely, an imposed wall temperature above the envelop regulation set-point.

The available experimental results will be exploited to calibrate and validate a predictive phase change solver, based on a volume of fluid technique and a thermal balance at the interface, which is currently under development.

\section{Acknowledgment}

The authors acknowledge the joint support of the Centre National d'Etudes Spatiales (CNES) and Air Liquide Advanced Technologies (ALAT). The laboratory LEGI is part of the LabEx Tec 21 (Investissements d'Avenir-Grant Agreement No. ANR11-LABX-0030).

\section{Nomenclature}

$$
\begin{aligned}
c_{\mathrm{p}} & =\text { fluid mass specific heat }\left(\mathrm{J} \mathrm{kg}^{-1} \mathrm{~K}^{-1}\right) \\
h & =\text { heat transfer coefficient }\left(\mathrm{W} \mathrm{m}^{-2} \mathrm{~K}^{-1}\right) \\
\dot{m}_{\text {inj }} & =\text { injection mass flow rate }\left(\mathrm{kg} \mathrm{s}^{-1}\right)
\end{aligned}
$$

$m_{\text {liq }}^{\text {init }}=$ initial liquid mass in the tank $(\mathrm{kg})$

$P_{\mathrm{atm}}=$ atmospheric pressure $(\mathrm{Pa})$

$\mathcal{P}_{\mathrm{c}}=$ tank heat load $(\mathrm{W})$

$P_{0}=$ tank initial pressure before self-pressurization $(\mathrm{Pa})$

$S=$ heat transfer exchange surface $\left(\mathrm{m}^{2}\right)$

$T_{\text {amb }}=$ ambient temperature in the experimental room $\left({ }^{\circ} \mathrm{C}\right)$

$T_{\text {ave }}=$ average temperature inside the tank $\left({ }^{\circ} \mathrm{C}\right)$

$T_{\text {env }}=$ envelope temperature $\left({ }^{\circ} \mathrm{C}\right)$

$T_{\text {inj }}=$ injection temperature $\left({ }^{\circ} \mathrm{C}\right)$

$T_{\text {sat }}=$ saturation temperature $\left({ }^{\circ} \mathrm{C}\right)$

$\beta=$ slope of the linear compensation factor applied to the envelope regulation

$\Delta T_{\text {jet/fluid }}=$ temperature imbalance between the subcooled jet and the fluid in the tank $\left({ }^{\circ} \mathrm{C}\right)$

$$
\rho=\text { fluid density }\left(\mathrm{kg} \mathrm{m}^{-3}\right)
$$

\section{References}

[1] Hartwig, J., Chato, D., McQuillen, J., Vera, J., Kudlac, M., and Quinn, F., 2014 "Screen Channel Liquid Acquisition Device Outflow Tests in Liquid Hydrogen," Cryogenics, 64, pp. 295-306.

[2] Knoll, R. H., Smolak, G. R., and Nunamaker, R. R., 1963, "Weightlessness Experiments With Liquid Hydrogen in Aerobee Sounding Rockets; Uniform Radiant Heating Heat Addition-Flight 1," NASA Technical Memorandum TM X-484.

[3] Hasan, M., Lin, C., Knoll, R., Bentz, M., and Meserole, J., 1993, "Nucleate Pool Boiling in the Long Duration Low Gravity Environment of the Space Shuttle," NASA Technical Memorandum 105973, Reston, VA, AIAA Paper No. 93-0465.

[4] Regetz, J. D., Conroy, M. J., and Jackson, R. G., 1964, "Weightlessness Experiments With Liquid Hydrogen in Aerobee Sounding Rockets; Uniform Radiant Heating Heat Addition-Flight 4," NASA Technical Memorandum TM X-873.

[5] Nunamaker, R. R., Corpas, E. L., and McArdle, J. G., 1963, "Weightlessness Experiments With Liquid Hydrogen in Aerobee Sounding Rockets; Uniform Radiant Heating Heat Addition-Flight 3," NASA Technical Memorandum TM X-872.

[6] Lin, C., Van Dresar, N. T., and Hasan, M., 1991, “A Pressure Control Analysis of Cryogenic Storage Systems," NASA Technical Memorandum TM 104409, AIAA Paper No. 91-2405.

[7] Bentz, D., 1993, "Tank Pressure by Jet Mixing Control in Low Gravity," Technical Report, NASA Contractor Report No. 191012.

[8] Hasan, M. M., Lin, C. S., Van Dresar, N., and Park, F., 1991, "SelfPressurization of a Flightweight Liquid Hydrogen Storage Tank Subjected to Low Heat Flux," Technical Report No. TM 103804.

[9] Stochl, R. J., and Knoll, R. H., 1991, "Thermal Performance of a Liquid Hydrogen Tank Multilayer Insulation System at Warm Boundary Temperatures of 630, 530 and 152 R," AIAA Paper No. 91-2400.

[10] Meserole, J., Jones, O., Brennan, S., and Fortini, A., 1987, "Mixing-Induced Ullage Condensation and Fluid Destratification," AIAA Paper No 1987-2018.

[11] Panzarella, C. H., and Kassemi, M., 2003, "On the Validity of Purely Thermodynamic Descriptions of Two-Phase Cryogenic Fluid Storage,” J. Fluid Mech., 484, pp. 41-68.

[12] Panzarella, C., Plachta, D., and Kassemi, M., 2004, "Pressure Control of Large Cryogenic Tanks in Microgravity," Cryogenics, 44(6-8), pp. 475-483.

[13] Barsi, S., and Kassemi, M., 2013, "Investigation of Tank Pressurization and Pressure Control—Part II: Numerical Modeling," ASME J. Therm. Sci. Eng. Appl., 5(4), p. 041006.

[14] Grayson, G., Lopez, A., Chandler, F., Hastings, L., Hedayat, A., and Brethour, J., 2007, "CFD Modelling of Helium Pressurant Effects on Cryogenic Tank Pressure Rise Rates in Normal Gravity," AIAA Paper No. 2007-5524.

[15] Barsi, S., and Kassemi, M., 2008, "Numerical and Experimental Comparisons of the Self-Pressurization Behavior of an LH2 Tank in Normal Gravity," Cryogenics, 48(3-4), pp. 122-129.

[16] Barsi, S., 2011, "Ventless Pressure Control of Cryogenic Storage Tanks," Ph.D. thesis, Case Western Reserve University, Cleveland, OH.

[17] Demeure, L., 2013, “Comportement Thermodynamique de Réservoirs d'ergols Cryogéniques," Ph.D. thesis, Université de Grenoble, Grenoble, France.

[18] Barsi, S., and Kassemi, M., 2009, "Investigation of Tank Pressure Control in Normal Gravity," AIAA Paper No. 2009-1148.

[19] Barsi, S., and Kassemi, M., 2013, "Investigation of Tank Pressurization and Pressure Control-Part I: Experimental Study," ASME J. Therm. Sci. Eng. Appl., 5(4), p. 041005.

[20] 3M, 2003, "Novec 1230 TM 3M-Product Information," Technical Report No. 98-0212-2667-9.

[21] Bullard, B., 1972, "Liquid Propellant Thermal Conditioning Test Program Final Report," NASA Report No. CR-72971.

[22] Thibault, J.-P., Corre, C., Demeure, L., and Mer, S., 2014, "Thermodynamic Control Systems for Cryogenic Propellant Storage During Long Missions," ASME Paper No. FEDSM2014-22217. 